\title{
DISCIPLINA E LIBERDADE NA FILOSOFIA DA EDUCAÇÃO DE IMMANUEL KANT
}

\author{
Adriana Alves Novaes Souza ${ }^{1}$
}

\section{Resumo}

O texto discute o nexo existente entre os conceitos de liberdade e disciplina na pedagogia kantiana, abordando algumas proposições do filósofo alemão acerca da natureza racional do homem e certas questões a ela relacionadas, tais como: esclarecimento, liberdade, autonomia e necessidade de disciplina (do corpo e da mente) para o melhor exercício dessa natureza. A metodologia está baseada na revisão de literatura, a partir da leitura de textos de Immanuel Kant, Jürgen Habermas e Sébastien Charles.

Palavras-chave: filosofia da educação, Kant, disciplina, liberdade.

\section{Resumen}

El artículo analiza el vínculo entre los conceptos de libertad y disciplina en la pedagogía kantiana, abordando algunas proposiciones sobre el filósofo alemán de la naturaleza racional del hombre y algunas cuestiones relacionadas con el mismo, tales como: la clarificación, la libertad, la autonomía y la necesidad de la disciplina (del cuerpo y de la mente) para el mejor ejercicio de esta naturaleza. La metodología se basa en la revisión de la literatura, a partir de la lectura de textos de Immanuel Kant, Jürgen Habermas y Sébastien Charles.

Palabras clave: filosofía de la educación, Kant, disciplina, libertad.

\section{Introdução}

Immanuel Kant é considerado o maior filósofo do Iluminismo alemão, cujo projeto filosófico, um marco ${ }^{2}$ da Filosofia da modernidade, está baseado, principalmente, no que é o ser humano, segundo a visão de homem como ser dotado de razão e liberdade. A construção desse conhecimento se dá por um processo complexo, que envolve o desenvolvimento da racionalidade social com fins determinados, ou seja, por uma razão instrumental

\footnotetext{
${ }^{1}$ Mestre em Educação pela Universidade Federal de Sergipe. E-mail: dria.novais.souza@gmail.com ${ }^{2}$ Conforme discussões feitas em sala de aula de Filosofia da Educação do Programa de PósGraduação em Educação, pelo Prof. Doutor em Filosofia, Edmilson Menezes, em 10 out. 2013, discutindo-se o projeto filosófico moderno.
}

SOUZA, Adriana Alves Novaes. Disciplina e Liberdade na Filosofia da Educação de Immanuel Kant. Revista Sul-Americana de Filosofia e Educação. Número 23: nov/2014-abr/2015, p. 4-12. 
que parta da construção e organização do pensamento (constructo da razão) e que evolua para o desenvolvimento desta como faculdade plena, complexa do indivíduo (HABERMAS, 2002, p. 4). Essa nova forma de vida racionalizada se caracteriza pela postura reflexiva em relação às tradições, por formas de agir universalizadas, por "modelos de socialização que se dirigem à formação de identidades abstratas do eu e que forçam a individualização dos adolescentes" (DURKHEIM e MEAD apud HABERMAS, 2002, p. 4).

Para se compreender a importância da Filosofia kantiana e das condições que conduziram as discussões para o campo da razão humana, é preciso, principalmente, compreender os princípios que fundamentaram a modernidade, seu conceito e origem, bem como todo o processo de evolução que possibilitou o projeto filosófico nela baseado.

No campo da educação, alguns questionamentos vão nortear o trabalho, tais como: Como Kant concilia a submissão à disciplina com o exercício da liberdade, obtida segundo o efetivo emprego da razão? Como é possível cultivar a liberdade, já que o constrangimento se faz necessário? Qual o nexo entre tais conceitos na visão do filósofo alemão?

Para responder a tais questões, empregou-se como metodologia a revisão de literatura, a partir da leitura de textos de Immanuel Kant, bem como de Jürgen Habermas e Sébastien Charles.

\section{Projeto moderno e ruptura com o pensamento metafísico da antiguidade}

A modernidade surge na Europa, por volta de 1500, marcada por acontecimentos singulares que fomentaram sua instauração e consolidação: a descoberta da América, acontecimento precipitado pela tomada de Constantinopla, o Renascimento, que propiciou um retorno ao pensamento clássico e, portanto, de retorno ao homem, a Revolução galilaica, que revolucionou a visão de posicionamento de mundo, a Reforma protestante, que questionou a hegemonia do catolicismo, dentre outros. Esses e outros acontecimentos contribuíram para uma abertura de ideias e de pensamentos voltados para o questionamento da lógica medieval, então vigente. A modernidade caracteriza-se então por seu aspecto histórico-temporal, de época orientada para o futuro, aberta ao novo que está por vir, que estabelece uma perspectiva para a consciência da história e que se reflete na utilização de expressões a ela relacionadas, tais como: "mundo novo", "novos tempos", "tempos modernos" (HABERMAS, 2002, p. 9).

Assim, a modernidade posiciona-se em relação ao passado (negando-o) e ao futuro (almejado); o presente, por sua vez, conforme Hegel (apud HABERMAS, 2002), é apenas uma transição efêmera, consumido na aceleração e expectativa do futuro, a quem ele relaciona ao Zeitgeist, o espírito do tempo, em constante passagem para um novo período.

A discussão sobre o conhecimento em torno da racionalidade humana somente foi possível a partir desse processo de reorganização do mundo ocidental, com a dissolução de "formas de vida tradicionais" (WEBER apud HABERMAS, 2002, p. 4), questionando-se paradigmas anteriormente enraizados, tais como a 
hegemonia religiosa, a legitimidade do Estado e uma visão de mundo calcada na materialidade, através da proposição de ideias voltadas para a subjetividade e para a racionalidade, dentro de uma estrutura de tempo cronológico, cujo futuro passa a ser direcionado historicamente (HABERMAS, 2002).

Com foco no progresso moral e científico, a modernidade traça novas marcas para o indivíduo, tais como liberdade, criticidade $e$ autonomia, manifestações que encaminham o homem para a busca pelo conhecimento por ele produzido e que lhe confere a consciência de si mesmo, tornando-o aquele que predica, que diz o mundo, que exerce uma função dentro da lógica, livre de dogmas, que questiona o conhecimento e verifica as condições de possibilidades de seu uso e seus limites, que, em suma, lhe permite exercer a crítica à matéria da ciência, a saber, o conhecimento.

Segundo Hegel (apud HABERMAS, 2002, p. 11), faz parte da consciência histórica da modernidade a delimitação entre "tempo mais recente" e "época moderna", quando a humanidade atinge "o último estágio da história", a atualidade da época em ruptura com o passado, num processo contínuo de renovação. Habermas defende a atualidade do projeto de modernidade, afirmando que ela apenas estará cumprida quando novo processo de ruptura ocorrer, no momento em que as expectativas começam a se afastar cada vez mais de todas as experiências feitas até então (KOSELLECK apud HABERMAS, 2002, p. 19), enfim, quando se esgotar todo o potencial de racionalização. Ainda discutindo Hegel, Habermas (2002, p. 25) caracteriza os novos tempos (ou mundo moderno) por sua subjetividade, por meio da liberdade e da reflexão, estabelecendo à subjetividade quatro conotações, imbricadas entre si: individualismo, direito de crítica, autonomia e idealismo. Habermas defende a retomada do projeto de emancipação segundo novas bases, ou seja, propõe um novo conceito de razão que promova as condições de liberdade de forma mais dialógica ou comunicativa.

A modernidade então promove maiores reflexões com base em concepções morais, centrada na autonomia do indivíduo, enquanto os filósofos, por sua vez, defendem a ideia de moral fundamentada não mais em valores religiosos, mas na compreensão do que é a natureza humana, ou natureza racional. Do ponto de vista filosófico, a Idade Moderna caracteriza-se pelo desencantamento do mundo, quando os homens perdem o medo de desvendar os supostos mistérios da realidade, de ruptura com o pensamento metafísico dos filósofos da antiguidade, substituindo-o pela ciência.

\section{Da relação com o conhecimento ou do condicionamento da razão}

Partindo para a discussão que Kant estabelece com o conhecimento, principalmente descritos no primeiro e no segundo prefácios de sua obra $A$ crítica da razão pura, quando então ele critica o pensamento metafísico por confundir os objetos de ideias, tais como Deus, alma e mundo, com conteúdos da razão, acreditando que existissem de fato. Kant trata da forma material da questão do saber, afirmando que, no conhecimento dos objetos, há sempre elementos que dependem do próprio objeto e constituem a matéria do conhecimento e há outros 
que dependem do sujeito e constituem sua forma. A matéria ou objeto, a posteriori, está relacionada aos dados fornecidos pelos sentidos e posterior à experiência, enquanto a forma é o conhecimento puro, relacionada ao sujeito a priori.

O conhecimento, então, pressupõe uma matéria a posteriori, proveniente das experiências do sujeito com os objetos e uma forma a priori imposta ao objeto pelo sujeito. O conhecimento, assim, gira em torno do sujeito e é o resultado da interação entre sujeito que conhece e objeto conhecido. Existem objetos que são apreensíveis pelo sujeito, outros que já foram apreendidos por ele e aqueles que nunca serão apreendidos. Isso significa que não conhecemos as coisas em si mesmas, de forma independente, mas conhecemos as coisas tal como as percebemos, segundo nossas estruturas mentais.

Para Kant, o conceito está subordinado ao condicionamento da razão (espaço/tempo) e a ideia não. Sob tal visão de mundo, ele estabelece como premissa a exposição de todo conhecimento ao livre e público exame, ou seja, somente será considerado como conhecimento aquilo que pode ser verificado, questionado, que satisfaça a busca por esse conhecimento ${ }^{3}$. Para o filósofo, as opiniões propostas pelo mundo devem passar incontestavelmente pelo crivo da razão, pois apenas esta é capaz de elaborar normas universais a serem obedecidas, com origem na própria razão. Essas normas, para o filósofo, devem ser obedecidas como deveres, noção que se confunde com a noção de liberdade, uma vez, ao obedecer às normas morais, o homem está obedecendo a uma liberdade da própria razão, que determina o que é correto ou não. A crítica da razão pura diz do conhecimento e a crítica da razão prática diz do homem e da ideia de liberdade. A educação está situada no campo da razão prática, enquanto que na razão pura ela se encontra como fenômeno pedagógico.

O exercício dessa razão, que permite ao homem dizer o que pensa, deve atender às situações em que ele se coloca diante do demais, obedecendo a dois princípios: o de uso público da razão e de uso privado, como Kant, de maneira brilhante, justifica. Quando qualquer pessoa, em posse de seu raciocínio, pode se expressar livremente, dizendo o que pensa, ela está fazendo valer o uso público de sua razão, mas, em certas situações de subordinação, o discurso desse indivíduo precisa obedecer às regras da instituição à qual está subordinado, o que se constitui no uso privado da razão, o que não quer dizer que ele tenha perdido sua autonomia, mas que ele reconhece as situações em que não lhe é permitido raciocinar livremente e expor esse raciocínio, mas que obedeça, como, por exemplo, possuir cargo público, oficial ou militar, ou em demais profissões que se exercem no interesse da comunidade. Fora de sua condição de funcionário e da subordinação a um comando superior, em condição de membro da comunidade, esse mesmo retoma seu direito de expor seu entendimento, resguardado de sua liberdade de expressão (KANT, 1985, p. 106).

\footnotetext{
${ }^{3}$ Em nota de rodapé do primeiro prefácio de sua Crítica da razão pura, Kant se refere a algumas queixas relacionadas ao modo superficial do pensamento da época e à decadência da ciência rigorosa, defendendo a validade da matemática e da física, por exemplo, sugerindo que todo conhecimento fosse então submetido ao rigor da retificação e da crítica.
} 
O indivíduo que consegue fazer uso de seu entendimento sem a direção de outro indivíduo passa de sua condição de menoridade e atinge a maioridade. É com a distinção entre uso público e privado que Kant assenta e aprofunda a sua definição de esclarecimento, que seria, então, a saída da condição de menoridade para a maioridade. Infelizmente, a saída da condição de menoridade não ocorre tão facilmente, uma vez que a covardia e a preguiça impedem que grande parte dos homens, embora tenham atingido sua fase adulta, biologicamente falando, não atingiram sua maioridade. Para Kant (1985, p. 100), o homem é o único culpado de sua menoridade, quando se deixa vencer pela indecisão e desânimo, uma vez que "é tão cômodo ser menor", deixar a cargo de outros que decidam, esforcem-se e/ou se encarreguem de tarefas indesejadas em seu lugar, que o homem simplesmente não deseja a maioridade por considerá-la difícil, afinal, para que pensar quando se pode pagar por isso? Uma das causas de tal pensamento está na educação recebida, repleta de cerceamentos e cuidados exagerados de seus tutores, os quais, à guisa de proteção ou até mesmo por comodidade, tomaram a si o cargo de minimizar da criança suas quedas, seus erros e sofrimentos. A menoridade, para esses indivíduos, afirma ele (idem, p. 102), torna-se uma segunda natureza, amada e acalentada.

\section{O nexo entre educação, esclarecimento, disciplina e liberdade em Kant}

O esclarecimento na visão kantiana é perfeitamente possível e até inevitável, quando se obedece ao direito de liberdade do indivíduo, embora existam situações em que o esclarecimento emerge mesmo em situações de controle, quando o homem, à revelia de qualquer tentativa de opressão de seus tutores (esses mesmos incapazes de esclarecimento), assume sua condição de maioridade e passa a fazer uso de seu entendimento de forma autônoma, livre. Nesse contexto, compreendese o papel fundamental da liberdade como mola propulsora do esclarecimento, que permite ao indivíduo o uso público de sua razão nas mais diversas questões e da saída de sua condição de menoridade. O esclarecimento em Kant é um projeto: a saída da menoridade, a tomada de decisões com coragem e sem necessidade da ajuda de outros, fazendo uso de seu próprio entendimento.

Nesse pressuposto, qual o papel da educação? Segundo Kant, educação está relacionada ao cuidado desde a infância, à disciplina e à instrução com a formação (1999, p. 441), constituindo-se como grande alavanca para o esclarecimento. É preciso cuidar do indivíduo, nutrindo seu corpo, protegê-lo dos perigos externos e, na medida em que vai se desenvolvendo entre os seus, protegelo até de si mesmo. Por vir ao mundo necessitado de cuidados, em estado bruto, o homem não terá, nas fases iniciais de sua existência, condições de determinar sua conduta, precisando de outros para fazê-lo por ele, mas Kant enfatiza que esse papel é dele e que, em determinado momento de sua existência, ele precisará formar por si mesmo seu projeto de conduta e as decisões que ora tomará dirão muito da orientação recebida nessas primeiras fases. Nesse caso, o papel da educação se fortalece e se constitui como base da formação inicial do indivíduo, como lugar profícuo para discussões e debates, para o exercício do olhar que 
semeará a crítica e a constituição da racionalidade, ou seja, a educação assume a responsabilidade de direcionamento da razão.

Questiona-se: é possível se educar dentro de tais parâmetros e incentivar que o homem atinja sua maioridade, uma vez que atingir o estado de esclarecimento requer que ele exerça sua liberdade de pensamento e crítica? Para Kant, a sujeição à norma moral é o reconhecimento de sua legalidade, conferida pela racionalidade humana. Ao considerar que um ato somente será moral quando regido por uma consciência autônoma e sob o senso do dever, o filósofo reforça o reconhecimento do dever como expressão de racionalidade humana, fonte legítima da moralidade (KANT, 1999).

Para Kant, o homem nem é bom nem mau, por não ser moral por natureza, mas dependendo da forma como é conduzido, pode pender para um ou outro estado (KANT, 1999, p. 492). Mas, a fim de conter seu pendor para o mal, ele cria formas de regulação, a partir de leis morais, regras, normas e da religião, que possuem uma moral implícita que atenda a seus interesses. Para Kant, a educação e a moral são intrínsecas. O que impede o homem de desviar-se de seu destino, de afastar-se de sua humanidade e dar vazão à sua animalidade é a disciplina. Kant enfoca a necessidade de submissão, desde tenra idade, do homem às suas próprias leis, motivo pelo qual as crianças são mandadas à escola o mais cedo possível, para o domínio do corpo e para aprender regras de conduta $e$ obediência, com vistas de, no futuro, conseguirem dominar seus caprichos. $\mathrm{O}$ grande desafio, de que Kant (1999, p. 442) trata com extrema habilidade, diz respeito à força da liberdade dentro do indivíduo: "mas o homem é tão naturalmente inclinado à liberdade que, depois que se acostuma a ela por longo tempo, a ela tudo sacrifica".

A necessidade de recorrer cedo à disciplina se fortalece diante desse aspecto, pois, de outra forma, seria impossível modificar o homem no futuro. Diferentemente de Rousseau, Kant não atribui a selvageria dos indígenas e outros nativos autóctones à sua tendência à liberdade, mas à rudeza animal, que não chegou a desenvolver sua humanidade na medida adequada. Se relegado à sua vontade, sem que lhe ofereçam resistências, o homem conservará sua selvageria por toda a vida (KANT, 1999, p. 442). Educação, nesse sentido, compreende cuidados e formação e esta última relaciona-se com a instrução e a disciplina, cuja falta é, para Kant, ainda mais danosa que a falta de cultura, cultura pode ser adquirida ao longo da vida, mas um estado de espírito selvagem, causado pela ausência total de regras é irremediável e permitir semelhante estrago às próximas gerações é ainda pior, uma vez que:

Um homem sem dúvida pode, no que respeita à sua pessoa, e mesmo assim só por algum tempo, na parte que lhe incumbe, adiar o esclarecimento [Aufklärung]. Mas renunciar a ele, quer para si mesmo quer ainda mais para sua descendência, significa ferir e calcar aos pés os sagrados direitos da humanidade (KANT, 1985, p. 110).

Isso porque os cuidados com formação (disciplina $e$ instrução) dizem respeito não apenas ao indivíduo em si, já que ele a recebe de outros homens, 
num processo contínuo em que homens formam as gerações futuras de outros homens. O que poderia ocorrer quando os instrutores das futuras gerações são, por sua vez, indisciplinados, preconceituosos, eles mesmos carentes de esclarecimento? O resultado seria catastrófico! " Ora, se os preconceitos se transformam pela educação, não será necessário trabalhar somente com as crianças, mas também com seus pais e seus preceptores, pois o círculo vicioso da ignorância só pode ser vencido na sua própria fonte" (CHARLES, 2011, p. 72). Kant vai além, propondo que a educação deva estar a cargo de pessoas de natureza superior, com resultados acima de quaisquer expectativas. Para ele, o segredo da perfeição humana está na educação, cujo projeto, bem elaborado, transforma-se em um nobre ideal, uma arte que precisa ser aperfeiçoada por várias gerações, num continuum perfeito, onde a anterior tem a responsabilidade com a posterior, enquanto esta última carrega consigo o dever de ser melhor que aquela: "tornar-se melhor, educar-se e, se é mau, produzir em si a moralidade: eis o dever do homem" (1999, p. 446 e 447).

A educação precisa então ser raciocinada no sentido de trabalhar a natureza humana de forma tal que lhe permita alcançar seu destino, nunca à mercê de interesses que destoem de seu objetivo maior, já descrito anteriormente, mas que seja feita por pessoas capazes, preparadas para tal fim, e, ainda, que o indivíduo encontre nos pais, na família, desde seu nascimento, o exemplo primário pelos quais deve se regular, motivo pelo qual Kant sugere o estudo da pedagogia, colocando-se a ciência em lugar do mecanicismo; caso contrário, uma geração pode causar um dano irreversível à seguinte, em um ciclo que, infelizmente, tende a se repetir. Habermas (2002) aponta para a responsabilidade histórica da geração presente, cujas ações predominam sobre as ações das gerações passadas e das quais precisará prestar contas em casos de omissões e intervenções futuras.

A responsabilidade pela educação, atribuída ao homem, decorre das consequências maléficas ou benéficas que podem provocar na vida das gerações futuras. Portanto, o desenvolvimento do processo educativo não pode ser mecânico, mas baseado numa conduta racional e num plano que ordene a ação. A pressão é inevitável:

De acordo com essa inversão, dois pensamentos podem se combinar: a ideia de que cada geração do presente carrega a responsabilidade não apenas pelo destino das gerações futuras, mas também pelo destino, sofrido na inocência, das gerações passadas (HABERMAS, 2002, p. 22).

Em Kant (1999, p. 448), encontramos a resposta para evitar esse dano às gerações futuras, quando direciona a pedagogia para a busca constante de um estado melhor que o atual, dentro da ideia de humanidade e aos fins a que se destina, o que nem sempre acontece porque muitos pais educam os filhos para o presente, para a ostentação, para a aparência e para o domínio sobre os demais, quando deveriam primar: a) pela disciplina, que impede que seu caráter se degenere e lhe prepara para o melhor convívio entre os seus; b) pela cultura, que lhe dará instrução e conhecimento; c) pela prudência, que confere estabilidade, 
civilidade e carisma, tão necessários no trato social e, por fim, d) pela moralidade, que lhe dará o discernimento de escolher os melhores fins e refutar o que é desprezível, independentemente de qualquer pregação. É muito importante a compreensão kantiana sobre a virtude, a qual não refuta o que é desprezível por ser pecado, mas porque avilta a moral.

Para Kant, a educação é condição sine qua non para a moral e o homem único ser que precisa ser educado. Em sua obra Sobre a pedagogia (1999), ele apresenta algumas ideias relacionadas à educação que dizem respeito aos cuidados com a infância, relacionados à alimentação, disciplina, formação e instrução, responsáveis pela distinção humana dos demais animais, cuidados que impedem as crianças de utilizarem suas vontades de maneira nociva, disciplinando-as para o bem-estar futuro.

\section{Considerações finais}

Quando se trata de disciplina, Kant apresenta um outro aspecto relacionado, muito controverso, mas que assume grande relevância para a educação, que é o constrangimento. Segundo ele (1999, p. 454), "um dos maiores problemas da educação é o poder de conciliar a submissão ao constrangimento das leis com o exercício da liberdade". As relações de sociabilidade do indivíduo e a necessidade de constrangimento e antagonismo são perfeitamente explicadas por Kant a partir da metáfora da árvore (1999, p. 448), a qual, quando isolada no meio de um campo não cresce direito, expande galhos longos, devido à falta de resistência aos movimentos, mas aquela que cresce no meio da floresta, devido à resistência das outras árvores, busca ar e luz e por isso cresce ereta. Isso a fortalece!

Para cultivar a liberdade necessária, a criança deve ser submetida ao constrangimento, para que, desde cedo, perceba que sua vontade estará sempre condicionada à resistência da sociedade, que ela não bastará a si mesma, mas precisará tolerar algumas privações no exercício de sua liberdade. A uma criança a quem nada se opõe, cujos desejos são satisfeitos desde sempre, a convivência em sociedade será penosa, uma vez que não aprendeu a condicionar sua liberdade à liberdade dos outros e faltam-lhe limites para compreender até que ponto seus propósitos podem ser alcançados sem cercear os dos demais.

O constrangimento, então, não deve ser tratado como negativo quando sua finalidade maior é ensinar a exercer a liberdade sem ajuda dos demais, uma liberdade que se traduz por autonomia de acordo com os princípios da racionalidade. Kant (1999, p. 475) defende que "deve haver regras para tudo aquilo que pode cultivar o entendimento", desde que se compreenda a diferença entre liberdade e natureza, pois o homem pode ser dotado de uma sólida constituição física, possuir um espírito bem formado, mas ser destituído de moral, uma pessoa má.

Nesse ponto, Kant dialoga com Crévier (1762) apud Charles (2011), pois este já enfatizava o preparo do corpo e da alma do educando para que este se preste mais facilmente às operações da alma e esta, por sua vez, facilitará as funções do corpo. A disciplina não gera senão um hábito, que desaparece com os anos, mas quando se acostuma a criança segundo máximas, tem-se a formação 
da cultura moral, que impede os defeitos e formam o caráter, mediante o sentido do que é bom ou mau.

Na proposição do filósofo, a liberdade é o fim, mas também o meio para o desenvolvimento do saber do homem e seu melhoramento pela educação em direção ao bem, depende, totalmente, do próprio homem. Em tempos de conflitos na escola provocados pela ausência de disciplina, uma revisitada nas noções kantianas pode ser bastante útil para a compreensão dessas $e$ de outras dificuldades enfrentadas pelo educador atual.

\section{Referências}

CHARLES, Sébastien. Paideia e filosofia no século das Luzes. In: MENEZES, Edmilson; OLIVEIRA, Everaldo de (org.). Modernidade filosófica: um projeto, múltiplos caminhos. São Cristóvão: Editora UFS, 2011.

HABERMAS, Jürgen. A consciência de tempo da modernidade e sua necessidade de autocertificação. In: O discurso filosófico da modernidade: doze lições. Trad. Luiz Sérgio Repa e Rodnei Nascimento. São Paulo: Martins Fontes, 2002.

KANT, Immanuel. Crítica da razão pura. $5^{\mathrm{a}}$ ed. Trad. Manuela P. dos Santos e Alexandre F. Morujão. Lisboa: Fundação Calouste Gulbenkian, 2001.

. Sobre a pedagogia. $2^{\mathrm{a}}$ ed. Trad. Francisco Cock. Piracicaba: Editora Unimep, 1999.

Resposta à pergunta: Que é esclarecimento? In: Trad. Raimundo Vier e Floriano de S. Fernandes. Petrópolis: Vozes, 1985. 